\title{
Tissue expression of Toll-like receptors 2 and 4 in sporadic human colorectal cancer
}

\author{
Yasuhiro Nihon-Yanagi $\cdot$ Kensuke Terai • \\ Takeyoshi Murano · Takayuki Matsumoto • \\ Shinichi Okazumi
}

Received: 15 November 2010 / Accepted: 20 July 2011 / Published online: 4 August 2011

(C) The Author(s) 2011. This article is published with open access at Springerlink.com

\begin{abstract}
Background Toll-like receptors (TLRs) play an important role in innate immunity by sensing a variety of pathogens and inducing acquired immunity. To test our hypothesis that dysregulation of innate immune responses acts to trigger carcinogenesis, we studied the expression of TLR2 and 4 in sporadic human colorectal cancer tissue.

Methods In specimens of cancerous and noncancerous colorectal tissue obtained at surgery, mRNA expression levels of TLR 2 and 4 were quantified by TaqMan real-time polymerase chain reaction and compared between the two types of tissue. To confirm TLR2 and TLR4 protein expression levels, immunohistochemical analysis was performed using the same samples.

Results TLR2 mRNA expression was significantly higher in cancerous tissue than in noncancerous tissue, while TLR4 mRNA expression did not differ significantly. Immunohistochemical analysis revealed stronger staining for TLR2 in cancerous mucosal epithelial cells than in noncancerous tissue. Staining for TLR4 in the lamina propria of the mucosa was equally weakly positive in noncancerous tissue and cancerous tissue. This TLR-specific difference in expression suggested that such expression does not only reflect a local inflammatory response to cancer infiltration, i.e., if this was the case, both TLR2 and 4 expression would probably be up-regulated. Our results suggest that TLR2
\end{abstract}

\footnotetext{
Y. Nihon-Yanagi $(\bowtie) \cdot$ S. Okazumi

Department of Surgery, Toho University Sakura Medical Center, Shimoshizu 564-1, Sakura, Chiba 285-8741, Japan

e-mail: nihonyanagi@ sakura.med.toho-u.ac.jp

K. Terai $\cdot$ T. Murano $\cdot$ T. Matsumoto

Research and Development, Toho University

Sakura Medical Center, Chiba, Japan
}

expression might be involved in sporadic colorectal carcinogenesis, whereas TLR4 is not.

Keywords Toll-like receptors (TLRs) · Colorectal cancer $\cdot$ Real-time polymerase chain reaction (real-time PCR) · Innate immunity

\section{Introduction}

Chronic inflammatory conditions (e.g., persistent infections) are known to be related to carcinogenesis in some organs [1-3]. Examples include chronic Helicobacter pylori gastritis and gastric cancer [1, 4, 5], chronic hepatitis or cirrhosis due to hepatitis $\mathrm{B}$ or $\mathrm{C}$ virus and hepatocellular carcinoma [1-3], and inflammatory bowel disease (IBD) and colorectal carcinoma $[6,7]$.

Ulcerative colitis and Crohn's disease are chronic IBDs of unknown causes. A growing body of evidence suggests that the Toll-like receptors (TLR) TLR2 and TLR4 on intestinal epithelium and mucosal macrophages in patients with these diseases are up-regulated as compared with healthy persons [8, 9]. Moreover, patients with longstanding IBD have an increased risk of colorectal cancer $[10,11]$.

As for gastric cancer, investigation of TLR expression on tumor cells of gastric carcinoma associated with $H$. pylori infection has revealed the expression of TLR4, 5, and 9 (TLR9 expression is rather weak.) [12].

TLRs are a family of receptors consisting of highly conserved molecules that sense pathogen-associated molecular patterns (PAMPs) and activate innate immune responses. These receptors thus play a key role in immunosurveillance $[6,13]$. Currently, 11 members of the TLR family have been identified $[14,15]$. TLRs are present on a variety of cells, 
mucosal epithelium, endothelial cells, and immune cells such as macrophages, dendritic cells, and $\mathrm{T}$ and $\mathrm{B}$ cells $[16,17]$. Triggering of TLRs, with the exception of TLR3, induces MyD88, an adaptor protein that elicits intracellular signal-transduction agents, activates tumor necrosis factor receptor-associated factor 6 (TRAF6), and finally activates NF- $\kappa$ B. MyD88 is essential for the production of proinflammatory cytokines $[18,19]$. A distinct profile of cytokines and chemokines is modulated by TLR-mediated inflammatory and immune responses [20].

Several studies have shown that activation of the innate immune system by engagement of TLRs to their ligands results in antitumor effects [21, 22]. However, the findings of some investigations do not support the antitumor effects of TLRs [23, 24].

We focused on inflammation-induced carcinogenesis as represented by carcinomas arising from chronic inflammatory disorders and hypothesized that tumorigenesis involves abnormal responses of host-innate immune systems to different kinds of antigens. Recent studies have clarified that TLRs are functionally associated with tumor progression in tumor cell lines; for example, engagement of TLRs increases tumor growth and tumor immune escape and also induces apoptosis resistance and chemoresistance in some tumor cells $[25,26]$. To gain a better understanding of the role of TLRs, we considered it practical to estimate the total amounts of TLRs in tissues in vivo because we assume that interactions among various cells are caused by intercellular signaling triggered by changes in TLR expression in the microenvironment of tumors, resulting in tumor progression or regulation.

Therefore, to gain insight into the roles of these relatively unexplored molecules, we initially studied the expression of TLR2 and 4 in cancerous and noncancerous colorectal tissues in patients with sporadic colorectal cancer. We also immunohistochemically analyzed the expression of these receptors to determine their distributions in each type of tissue.

\section{Materials and methods}

Human tissue samples and internal control

Surgical specimens of colorectal tissues were obtained from 50 patients with colorectal carcinoma at Toho University Sakura Medical Center after their agreement. About $30 \mathrm{mg}$ each of cancerous tissue (CT) and noncancerous tissue (NCT), situated proximally to the tumor and macroscopically free of disease (a subsequent microscopic analysis showed no cancer cells), was taken immediately after surgery. TLR2 and TLR4 mRNA expression in each tissue sample was measured by quantitative real-time PCR.
CT specimens consisted mainly of the surface layer of the tumor, and NCT specimens consisted mainly of the surface layer of the normal mucosal.

To select the optimal internal control, we used TaqMan ${ }^{\circledR}$ Human Endogenous Control Plate (Applied Biosystems Inc.), which contains TaqMan primers and probes for 11 commonly used housekeeping (HK) genes and 1 internal positive control sequence. NCT and CT specimens obtained from patients with colorectal cancer were used as test specimens ( 8 samples/4 patients) to determine the most suitable internal references. One of the NCT samples was used as a calibrator. Following the manufacturer's instructions, we investigated potential controls and chose one gene, $\beta$-actin (BA) as an internal control. Relative quantification was performed using this gene. Then TLR2 and 4 expression levels were compared between the NCT and CT specimens.

This study was approved by the Ethics Committee of Toho University Sakura Medical Center.

\section{Patients and subgrouping}

Table 1 shows the characteristics of 50 patients whose tumors were analyzed by real-time PCR (Table 1). The 50 patients were grouped according to the histopathological stage (pStage) of their tumors, based on the TMN classification of the International Union against Cancer (UICC). TLR2 and 4 expression of NCTs and CTs was assessed according to pStage. Tumors of pStage II A or pStage II B were collectively grouped together as pStage II, and tumors of pStage III A, pStage III B, and pStage III C were grouped together as pStage III because of the small numbers of samples. Differences in TLR2 and 4 expression among each of these pStages were analyzed for both NCTs and CTs. We also measured TLR2 and 4 expression in different parts of the colon from which the primary carcinoma arose and compared expression levels between the proximal colon (ascending colon and cecum) and the distal colon (sigmoid colon and rectum).

\section{Real-time PCR}

RNA was extracted using an RNeasy ${ }^{\circledR}$ Plus Mini kit (QIAGEN Ltd.) according to the manufacturer's protocol. Total RNA concentrations were measured by the absorbance measurement method, and a total of $1 \mu \mathrm{g}$ RNA was used to synthesize cDNA. The cDNA was synthesized with an Affinity Script ${ }^{\circledR}$ QPCR cDNA synthesis kit (Stratagene Ltd.) following the manufacturer's protocol and was used for quantitative real-time PCR.

Quantitative real-time PCR was performed using a Stratagene Mx3000P ${ }^{\circledR}$ QPCR System with TaqMan ${ }^{\circledR}$ Gene Expression Master Mix. We used TaqMan ${ }^{\circledR}$ Gene Expression Assays primers and probes (Applied Biosystems Inc.). 
Table 1 Characteristics of patients

\begin{tabular}{|c|c|c|c|c|}
\hline Age & \multicolumn{4}{|c|}{ Average, 67.8 years (ranged from 52 to 90 years) } \\
\hline Sex & \multicolumn{4}{|c|}{ Male, 22 cases female, 28 cases } \\
\hline $\begin{array}{l}\text { Tumor } \\
\text { location }\end{array}$ & \multicolumn{4}{|c|}{$\begin{array}{l}\text { Cecum, } 3 \text { cases ascending, } 2 \text { cases transverse, } \\
1 \text { case }\end{array}$} \\
\hline & \multicolumn{4}{|c|}{$\begin{array}{l}\text { Descending, } 2 \text { cases sigmoid, } 7 \text { cases } \\
\quad \text { rectum, } 27 \text { cases }\end{array}$} \\
\hline Histological & \multicolumn{4}{|c|}{ Tubular adenocarcinoma, 48 cases } \\
\hline & \multicolumn{4}{|c|}{ (well, 12 cases well-mod., 2 cases mod., 34 cases) } \\
\hline & \multicolumn{4}{|c|}{ Mucinous adenocarcinoma, 1 case } \\
\hline & \multicolumn{4}{|c|}{ Signet-ring cell, 1 case } \\
\hline $\mathrm{pT}^{\mathrm{a}}$ & \multicolumn{4}{|c|}{ pT 1,4 cases pT 2,5 cases pT 3,37 cases pT 4,4 cases } \\
\hline pStage $^{\mathrm{a}}$ & \multicolumn{4}{|c|}{ I, 7 cases II, 22 cases (IIa, 19 cases IIb, 3 cases) } \\
\hline & \multicolumn{4}{|c|}{$\begin{array}{l}\text { III, } 15 \text { cases (IIIa, } 2 \text { cases IIIb, } 10 \text { cases IIIc, } \\
3 \text { cases) IV, } 6 \text { cases }\end{array}$} \\
\hline \multicolumn{5}{|c|}{ a TMN classification (UICC) } \\
\hline \multicolumn{2}{|l|}{ Product type } & Assay ID & $\begin{array}{l}\text { Gene } \\
\text { symbol }\end{array}$ & Gene name \\
\hline \multicolumn{2}{|c|}{$\begin{array}{l}\text { Taqman }(\mathrm{R}) \text { Gene } \\
\text { Expression Assays }\end{array}$} & Hs00610101_m1 & TLR2 & $\begin{array}{l}\text { Toll-like } \\
\quad \text { receptor } 2\end{array}$ \\
\hline \multicolumn{2}{|c|}{$\begin{array}{l}\text { Taqman }(\mathrm{R}) \text { Gene } \\
\text { Expression Assays }\end{array}$} & Hs00152939_m1 & TLR4 & $\begin{array}{l}\text { Toll-like } \\
\text { receptor } 4\end{array}$ \\
\hline \multicolumn{2}{|c|}{$\begin{array}{l}\text { Taqman }(\mathrm{R}) \text { Gene } \\
\text { Expression Assays }\end{array}$} & Hs99999903_m1 & ACTB & Actin, beta \\
\hline
\end{tabular}

The thermal profile was precycling heat activation at $95^{\circ} \mathrm{C}$ for $10 \mathrm{~min}$, followed by $95^{\circ} \mathrm{C}$ for $15 \mathrm{~s}$ and $60^{\circ} \mathrm{C}$ for $60 \mathrm{~s}$ for a total of 40 cycles. Relative quantification of the total gene products in each sample was done by $\Delta \Delta \mathrm{Ct}$ analysis. All samples were run in duplicate.

The primers and probes used in this study can be found through the Assay ID in Table 2 (available online at https:// www.products.appliedbiosystems.Com/ab/en/US/adirect/ab: jsessionid=vLDgk3bp7kHLc1 yz1nr8tVyg3WtnmlGpYLv 3LCQNBJpT26wpGpGQ!-1852324903).

Immunohistochemistry

Four-micrometer-thick sections of paraffin-embedded human specimens of normal colon and cancer were prepared from tissue obtained at colectomy. Antigen retrieval was done using Target Retrieval Solution, pH 9.0 (DAKO, Japan), after deparaffinization and hydration of the slides. The slides were boiled at $95^{\circ} \mathrm{C}$ for $40 \mathrm{~min}$ and then cooled for $20 \mathrm{~min}$ at room temperature. Endogenous peroxidase activity was blocked by treatment with peroxidase-blocking solution $\left(\right.$ REAL $^{\mathrm{TM}}$, DAKO). After washing with TBS, the
Table 3 TLR2 and TLR4 expression compared between groups

\begin{tabular}{|c|c|c|}
\hline & $\operatorname{NCT}(n=)$ & $\mathrm{CT}(n=)$ \\
\hline \multicolumn{3}{|c|}{ a Expression of TLR2 and 4 in NCT and CT } \\
\hline TLR2 & $2.61 \pm 1.82(49)$ & $6.60 \pm 4.15^{* * *}(50)$ \\
\hline TLR4 & $1.61 \pm 1.04(50)$ & $2.17 \pm 2.22(50)$ \\
\hline \multicolumn{3}{|c|}{ b TLR2 and 4 expression in histological stages } \\
\hline TLR2 (pStage I) & $1.76 \pm 0.96(7)$ & $7.02 \pm 4.55^{*}(7)$ \\
\hline TLR4 (pStage I) & $1.14 \pm 0.43(7)$ & $2.10 \pm 1.41(7)$ \\
\hline TLR2 (pStage II) & $2.89 \pm 2.05(21)$ & $10.90 \pm 8.61 * *(22)$ \\
\hline TLR4 (pStage II) & $1.11 \pm 0.55(22)$ & $1.82 \pm 1.74(22)$ \\
\hline TLR2 (pStage III) & $4.02 \pm 3.19(15)$ & $7.73 \pm 5.55^{* *}(15)$ \\
\hline TLR4 (pStage III) & $1.72 \pm 0.78(15)$ & $1.33 \pm 1.09(15)$ \\
\hline TLR2 (pStage IV) & $1.77 \pm 1.06(6)$ & $5.59 \pm 1.94 * *(6)$ \\
\hline TLR4 (pStage IV) & $1.67 \pm 1.04(6)$ & $3.50 \pm 3.33(6)$ \\
\hline \multicolumn{3}{|c|}{ c TLR 2 and 4 expression in different parts of the colorectum } \\
\hline TLR2 (proximal colon) & $3.69 \pm 2.05(13)$ & $8.83 \pm 5.46^{*}(13)$ \\
\hline TLR2 (distal colon) & $2.09 \pm 1.20(34)$ & $8.41 \pm 7.78 * * *(34)$ \\
\hline TLR4 (proximal colon) & $0.88 \pm 0.46(34)$ & $1.84 \pm 1.07 *(34)$ \\
\hline TLR4 (distal colon) & $1.75 \pm 1.00(13)$ & $1.54 \pm 1.21(13)$ \\
\hline
\end{tabular}

Data are shown as mean $\pm \mathrm{SD}$

$* P<0.05, * * P<0.01, * * * P<0.001$

slides were incubated at room temperature in a moist chamber for 45 min with TLR4 antibody (1:100 dilution; TLR4 Mouse Anti-human Monoclonal [6B357.1a] Antibody-LSB2070-LifeSpan, Bioscience) and TLR2 antibody (1:50 dilution; monoclonal antibody, clone 1030A5. 138, Abnova Corporation). After washing with TBS, the slides were treated with Envision (Dako Chemo-Mate; Dako Japan Inc., Kyoto, Japan) for $30 \mathrm{~min}$, followed by color development in 3,3 diaminobenzidine tetrahydrochloride (Dako Japan Inc., Kyoto, Japan). Finally, the slides were lightly counterstained with hematoxylin. Isotype control immunoglobulin G1 (IgG1) and IgG2b antibodies (DAKO, Japan) were used as negative controls.

The degrees of expression of TLR2 and TLR4 in the specimens were evaluated by two experienced pathologists in our hospital and classified microscopically as weak or strong.

\section{Statistical analysis}

Data are expressed as means $\pm \mathrm{SD}$. Mean values were compared between groups with the use of unpaired Student's $t$-tests with two-tailed $P$ values by StatMate III (ATMS Co., Ltd., Tokyo, Japan). $P$ values of less than 0.05 were considered to indicate statistical significance. We also used Kruskal-Wallis test for interstage comparisons $(P<0.05)$. 

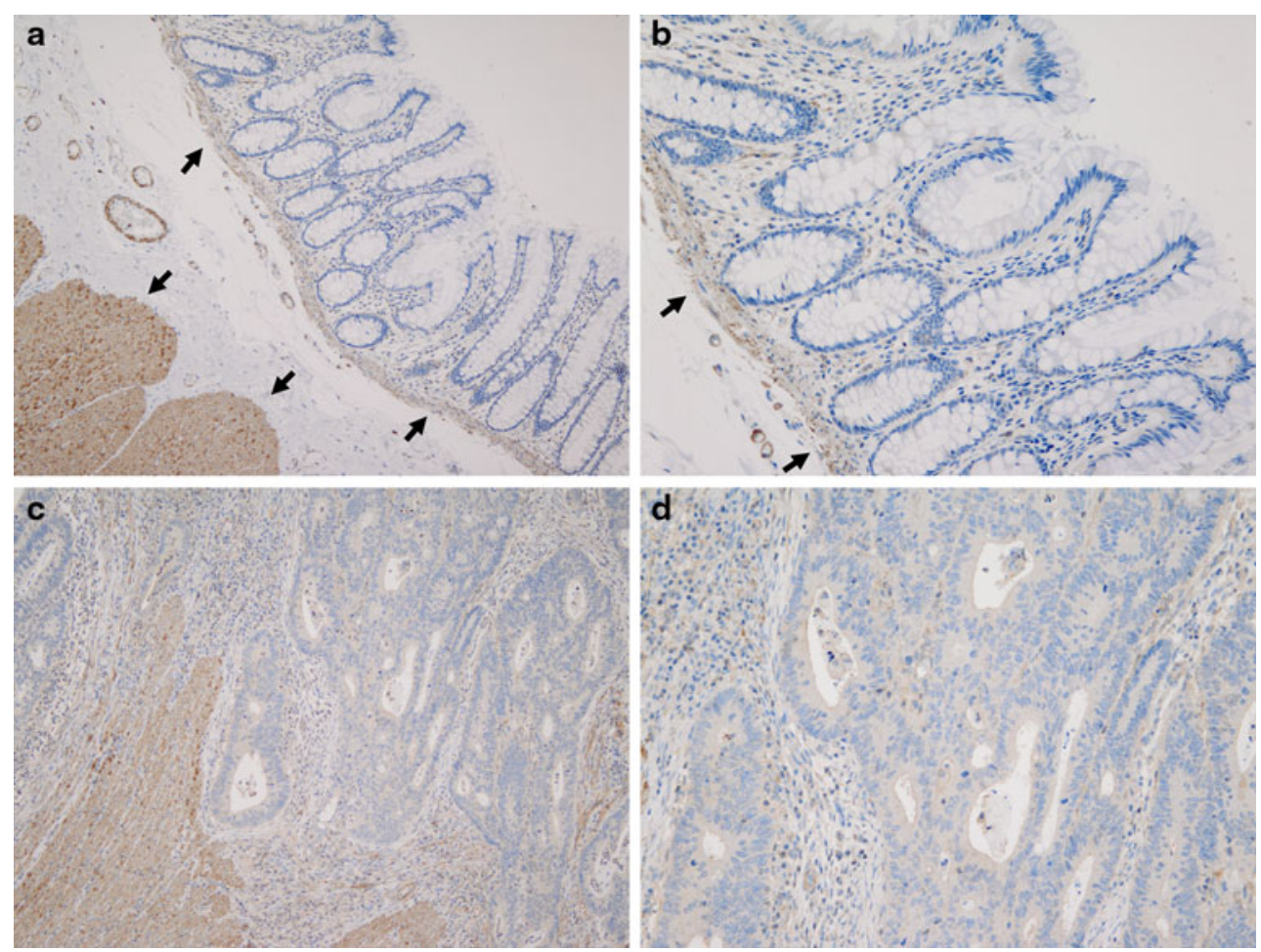

Fig. 1 Immunohistochemistry of TLR4 in NCT $(\times 10, \mathbf{a})(\times 20, \mathbf{b})$ and CT $(\times 10, \mathbf{c})(\times 20, \mathbf{d})$. All layers of the tissue specimens were stained, and TLR4 was strongly detected in the proper muscular layer and the

proper mucosal layer (arrows) (a, c). TLR4 was less positively stained in the lamina propria of the mucosa in both NCT and CT $(\mathbf{b}, \mathbf{d})$

\section{Results}

\section{Expression of TLR2 and 4 in NCT and CT}

Expression of TLR4 in NCT and CT was confirmed in all 50 patients by real-time PCR. There was no significant difference in TLR4 expression between NCT and CT (Table 3a). TLR2 mRNA expression was also confirmed in all $50 \mathrm{CTs}$ and $49 \mathrm{NCTs}$ on real-time PCR. TLR2 expression was significantly higher in CT than in NCT $(P<0.001$; Table 3a).

Analysis of TLR2 and 4 expression in histological stages

TLR2 and 4 expression was compared between NCT and $\mathrm{CT}$ according to pStage. There was no other significant difference in TLR4 expression between NCT and CT for any pStage (Table 3b). TLR2 expression was significantly higher in CT than in NCT for any pStage (Table 3b).

Interstage comparisons of TLR2 and 4 expression in NCTs and CTs

Interstage differences in TLR2 and TLR4 expression were analyzed in NCT and CT (Table 3b). In both NCT and CT,

there was no significant difference in TLR4 expression between $\mathrm{pStages}$.

In both NCT and CT, TLR2 expression was rather high in pStage II and III than in other pStages. However, there was no significant difference in TLR2 expression between pStages.

Analysis of TLR2 and 4 expression in different parts of the colorectum

We compared TLR 2 and 4 expression between NCT and CT in two different parts of the bowel, i.e., the distal colon (the rectum and the sigmoid colon) $(n=34)$ and the proximal colon (the ascending colon and the cecum) $(n=13)$, since there was no significant difference in TLR2 and TLR4 expression between pStages. There was no significant difference in TLR4 expression between NCT and CT in the distal part of the colon, but was higher in CT than in NCT in the proximal part of the colon $(P<0.05$; Table $3 \mathrm{c})$.

TLR2 expression was significantly higher in CT than in NCT in both the distal and proximal colon (distal colon: $P<0.001$; proximal colon: $P<0.05$, Table $3 \mathrm{c}$ ).

Immunohistochemical analysis

Immunohistochemical analysis of TLR2 and 4 was performed using the same samples of NCT and CT as real-time 

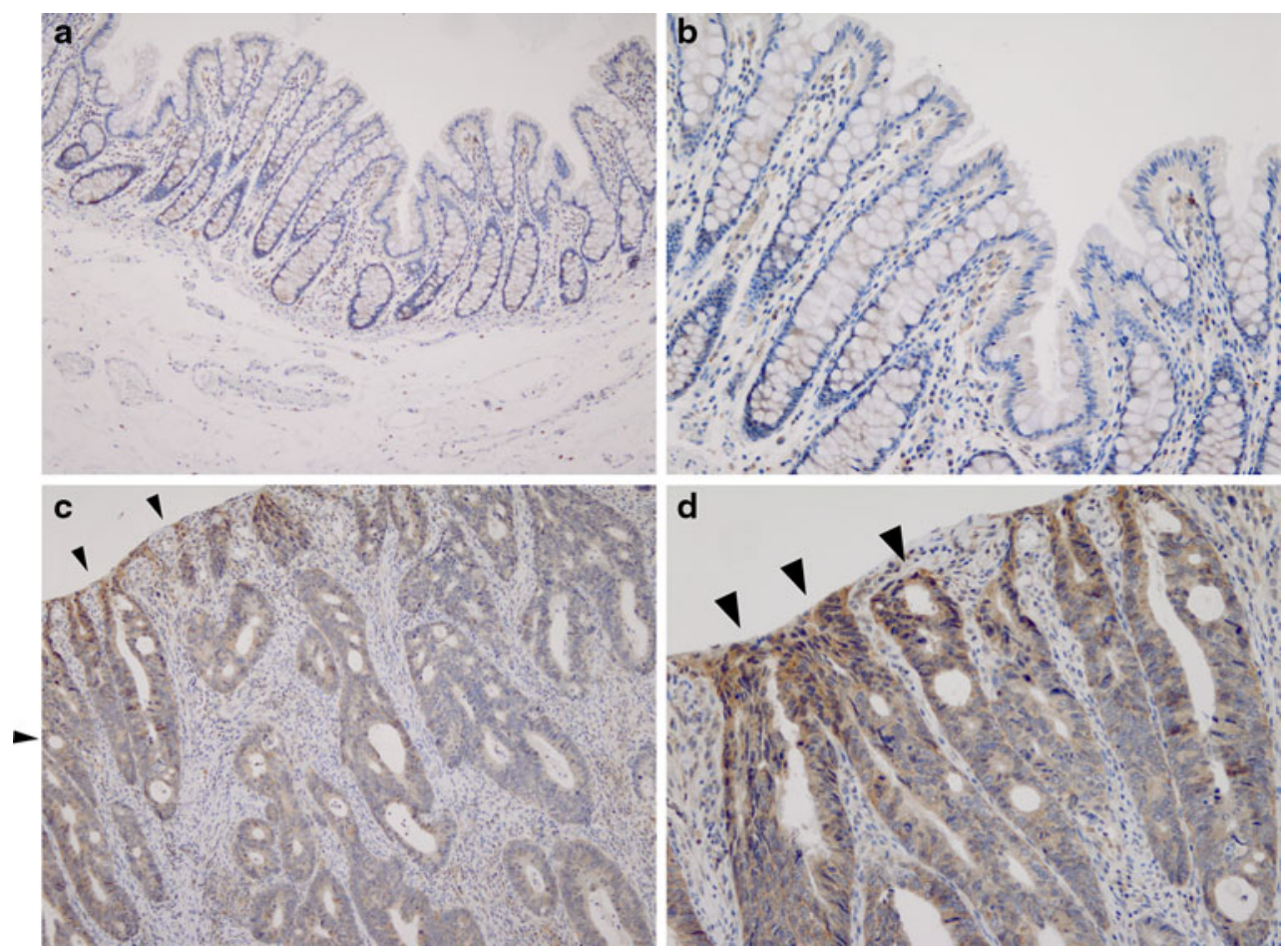

Fig. 2 Immunohistochemistry of TLR2 in $\operatorname{NCT}(\times 10, \mathbf{a})(\times 20, \mathbf{b})$ and CT $(\times 10, \mathbf{c})(\times 20, \mathbf{d})$. All layers of the tissue specimens were stained, and TLR2 expression in mucosal epithelial cells was stronger in CT than in NCT (arrow heads). Expression of TLR2 in the lamina propria was weakly positive in both NCT and CT $(\mathbf{a}, \mathbf{b}, \mathbf{c}, \mathbf{d})$
PCR to determine protein expression levels. All layers of the tissue specimens were stained, and TLR4 was strongly detected in the proper muscular layer and the proper mucosal layer. TLR4 was less positively (weakly) stained in the lamina propria of the mucosa in both NCT and CT (Fig. 1a, $\mathrm{b}, \mathrm{c}, \mathrm{d})$. In contrast, TLR2 expression in mucosal epithelial cells was strongly detected in CT and weakly in NCT. Expression of TLR2 in the lamina propria was weakly positive in both NCT and CT (Fig. 2a, b, c, d).

\section{Discussion}

In the present study, TLR4 expression did not differ significantly between NCT and CT. Moreover, there was no significant difference in TLR4 expression between NCT and CT in any each histological stage. In contrast to TLR4, TLR2 was significantly up-regulated in CT as compared with NCT. TLR2 expression was significantly higher in CT in each pStage of cancer as well. It was thought that the present study was not biased by pStage.

Immunohistochemical analysis showed similar weak positive TLR4 expression in NCT and CT in the lamina propria of the mucosa. TLR2 expression was more strongly positive in CT than in NCT. The site of expression was localized: TLR2 was strongly expressed in mucosal epithelial cells and weakly expressed in mucosal infiltrating lymphocytes. Indeed, these results are intriguing because both TLR4 and 2 would be expected to be up-regulated in CT as compared with NCT if increased expression was caused solely by inflammatory cell infiltration in response to CT. Fukata et al. [24] have reported that TLR4 expression might be a risk factor for tumorigenesis because TLR4 is overexpressed in colitis-associated adenocarcinoma (CAC) in patients with IBD. However, our findings do not fully support their results. TLR4 recognizes gram-negative bacteria by binding LPS, a membrane component of gramnegative bacteria. TLR4 is also now known to recognize other endogenous ligands [13, 19]. TLR2 recognizes cell membrane components of gram-positive bacteria, peptidoglycan, zymosan, and bacterial lipopeptides by forming heterodimers with other TLR family members [9, 27, 28]. On the basis of these findings, we assumed that no dramatic increase in TLR4 expression levels in cancerous colorectal tissues suggests that TLR4 is minimally or rarely involved in sporadic colorectal carcinogenesis as compared with CAC or that TLR4 expression is regulated by some special systems in CT. Up-regulation of TLR2 in CT implies that TLR2 may try to potentiate compensatory immune responses in the presence of restricted TLR4 expression in the tumor microenvironment or that some TLR2-specific ligands (e.g., gram-positive bacteria) may be responsible 
for carcinogenesis of the large intestine. These findings may provide clues to the mechanisms of carcinogenesis in the tissue microenvironment.

As for differences in expression according to the pStage of cancer, expression pattern of TLR2 in both NCT and CT was rather high in pStage II and III than in other pStages, but TLR4 expression pattern was in disorder. Because up-regulation of TLRs is thought to have a role in immune activity, it seems that immune response in association with TLR2 is most strongly activated in pStage II or III, followed by a decrease in immune activity in pStage IV. Our results may also imply a link between the regression of TLR2 expression in pStage IV and the mechanism of distant metastasis. However, there was no significant difference in TLR2 expression between pStages. It will be required a larger number of samples to analyze.

Ortega-Cava et al. [6] reported that TLR4 expression was high in the distal colon of normal mice. In contrast, TLR2 was predominantly expressed in the proximal segment of the colon. A similar distribution of TLR expression was confirmed in a colitic mouse model. In the present study, TLR2 expression in NCT was significantly higher in the proximal colon than in the distal colon. TLR4 expression in NCT was significantly higher in the distal colon than in the proximal colon. These results are consistent with the findings of Ortega-Cava et al. On the other hand, there was no significant difference in TLR2 and 4 expression between the proximal colon and the distal colon in CT. These expression patterns differed from those of the colitic mouse model of Ortega-Cava et al. Since CAC arises from IBD, the difference in the TLR2, 4 expression patterns suggests that the etiology of CAC and sporadic colorectal cancer differ.

In conclusion, to our knowledge, this is the first study to estimate TLR2 and 4 mRNA expression in sporadic colorectal cancer tissue obtained surgically from patients, not cancer cell lines alone, by means of real-time PCR and to compare such levels with those in NCT. Interestingly, our study unexpectedly demonstrated no apparent up-regulation of TLR4 in CT, in contrast to patients with CAC. Only TLR2 expression was up-regulated in CT. Although fully understanding the relation between innate immunity and carcinogenesis remains, the present work may provide new insights into the roles of TLRs in the development of colorectal cancer.

Acknowledgments The authors thank Takeo Asato for his histological assistance. This work was supported in part by a grant of Cancer Research Funds for Patients and Family from Medical treatment and Welfare Network Chiba, Japan.

Conflict of interest The authors disclose no conflicts.
Open Access This article is distributed under the terms of the Creative Commons Attribution Noncommercial License which permits any noncommercial use, distribution, and reproduction in any medium, provided the original author(s) and source are credited.

\section{References}

1. Kuper H, Adami HO, Trichopoulos D (2000) Infections as a major preventable cause of human cancer. J Intern Med 248:171-183

2. Balkwill F, Mantovani A (2001) Inflammation and cancer: back to Virchow? Lancet 357:539-545

3. Coussens LM, Werb Z (2002) Inflammation and cancer. Nature 420:860-867

4. Ernst PB, Takaishi H, Crowe SE (2001) Helicobacter pylori infection as a model for gastrointestinal immunity and chronic inflammatory disease. Dig Dis 19:104-111

5. Peek RM, Blaser MJ (2002) Helicobacter pylori and gastrointestinal tract adenocarcinomas. Nat Rev Cancer 2:28-37

6. Ortega-Cava CF, Ishihara S, Rumi MAK, Kawashima K, Ishimura N, Kazumori H, Udagawa J, Kadowaki Y, Kinoshita Y (2003) Strategic compartmentalization of Toll-like receptor 4 in the mouse gut. J Immunol 170:3977-3985

7. van der Woude CJ, Moshage H, Homan M, Klebeuker JH, Jansen PLM, van Dekken H (2003) Expression of apoptosis related proteins during malignant progression in chronic ulcerative colitis. J Clin Pathol 58:811-814

8. Cario E, Podolsky DK (2000) Differential alternation in intestinal epithelial cell expression of Toll-like receptor 3 (TLR3) and TLR4 in inflammatory bowel disease. Infect Immun 68:7010-7017

9. Frolova L, Drastich P, Rossmann P, Klimesova K, TlaskalovaHogenova H (2008) Expression of Toll-like receptor 2 (TLR2), TLR4, and CD14 in biopsy samples of patients with inflammatory bowel disease: upregulated expression of TLR2 in terminal ileum of patients with ulcerative colitis. J Histochemo Cytochemo $56: 267-274$

10. Katsanos KH, Vermeire S, Christodoulou DK, Riis L, Wolters F, Odes S, Freitas J, Hoie O, Beltrami M, Fornaciari G, Clofent J, Bodini P, Vatn M, Nunes PB, Moum B, Munkholm P, Limonard C, Stockbrugger R, Rutgeerts P, Tsianos EV (2007) Dysplasia and cancer in inflammatory bowel disease 10 years after diagnosis: results of a population-based European collaborative follow-up study. Digestion 75:113-121

11. Xie J, Itzkowitz SH (2008) Cancer in inflammatory bowel disease. World J Gastroenterol 14:378-389

12. Schmasser B, Andrulis M, Endrich S, Müller-Hermelink H, Eck M (2005) Toll-like receptors TLR4, TLR5 and TLR9 on gastric carcinoma cells: An implication for interaction with Helicobacter pylori. Int J Med Microbil 295:179-185

13. Miyake K (2007) Innate immune sensing of pathogens and danger signals by cell surface Toll-like receptors. Semin Immunol 19: 3-10

14. Merrell MA, Ilvesaro JM, Lehtonen N, Sorsa T, Gehrs B, Rosenthal E, Chen D, Shackley B, Harris KW, Selander KS (2006) Tolllike receptor 9 agonists promote cellular invasion by increasing matrix metalloproteinase activity. Mol Cancer Res 4:437-447

15. Garay RP, Viens P, Bauer J, Normier G, Bardou M, Jeannin J, Chiavaroli C (2007) Cancer relapse under chemotherapy: why TLR2/4 receptor abonists can help. Eur J Pharmacol 563:1-17

16. Zarember KA, Godowski PJ (2002) Tissue expression of human Toll-like receptors and differential regulation of Toll-like receptor mRNAs in leukocytes in response to microbes. Their products, and cytokines. J Immunol 168:554-561

17. Zhang R, Li Y, Beck PL, McCafferty D-M (2007) Toll-like receptor 4 regulates colitis-associated adenocarcinoma development in 
interleukin-10- deficient (IL-10 ${ }^{-l-}$ ) mice. Biochem Soc Trans 35:1375-1376

18. Medzhitov R, Preston-Hurlburt P, Janeway CA Jr (1997) A human homologue of the drosophila Toll protein signals activation of adaptive immunity. Nature 388:394-397

19. Takeda K, Kaisho T, Akira S (2003) Toll-like receptors. Annu Rev Immunol 21:335-376

20. Rhee SH, Keates AC, Moyer MP, Pothoulakis C (2004) MEK is a key modulator for TLR5-induced interleukin- 8 and MIP3 $\alpha$ gene expression in non-transformed human colonic epithelial cells. J Biol Chem 24:25179-25188

21. Okamoto M, Sato M (2003) Toll-like receptor signaling in anticancer immunity. J Med Invest 50:9-24

22. Seya T, Akazawa T, Uehori J, Matsumoto M, Azuma I, Toyoshima K (2003) Roll of Toll-like receptors and their adaptors in adjuvant immunotherapy for cancer. Anticancer Res 23:43694376

23. Pidgeon GP, Harmey JH, Kay E, Da Costa M, Redmond HP, Bouchier-Hayes DJ (1999) The role of endotoxin/lipopolysaccharide in surgically induced tumour growth in a murine model of metastatic disease. Br J Cancer 81:1311-1317
24. Fukata M, Chen A, Vamadevan AS, Cohen J, Breglio K, Krishnareddy S, Hsu D, Xu R, Harpaz N, Dannenberg AJ, Subbaramaiah K, Cooper HS, Itzkowitz SH, Abreu MT (2007) Toll-like receptor-4 promotes the development of colitisassociated colorectal tumors. Gastroenterology 133:1869-1881

25. Liu CH, Chang S, Narko K, Trifan OC, Wu M, Smith E, Haudenschild C, Lane TF, Hla T (2001) Over expression of cyclooxygenase- 2 is sufficient to induce tumorigenesis in transgenic mice. J Biol Chem 276:18563-18569

26. Kelly MG, Alvero AB, Chen AR, Silasi D, Abrahams VM, Chan S, Visintin I, Rutherford T, Mor G (2006) TLR-4 signaling promotes tumor growth and paclitaxel chemoresistance in ovarian cancer. Cancer Res 66:3859-3868

27. Schwandner R, Dziarski R, Wesche H, Rothe M, Kirschning CJ (1999) Peptidoglycan-and lipoteichoic acid-induced cell activation is mediated by Toll-like receptor 2. J Biol Chem 274:1740617409

28. Underhill DM, Ozinsky A, Smith KD, Aderem A (1999) Toll-like receptor-2 mediates mycobacteria-induced proinflammatory signaling in macrophages. Proc Natl Acad Sci USA 96:1445914463 